\title{
Por uma pragmática da inutilidade, ou o valor do inframince ${ }^{1}$
}

Erin Manning

Resumo: Duchamp descreve o inframince ${ }^{2}$ como "o mais ínfimo dos intervalos, ou a mínima das diferenças" (DUCHAMP apud PERLOFF, 2002, p. 101). Tomando o trabalho e a proposição de Duchamp no sentido de que o inframince não pode ser descrito como tal - "dele só é possível dar exemplos" (DUCHAMP apud DE DUVE, 1991, p. 160) -, este artigo explora como ele chega à expressão e pergunta como seria uma política do inframince. Ponto chave dessa exploração é saber de que outra forma pode o valor ser definido e como repensar esse conceito compõe com a noção de pragmática especulativa.

Palavras-chave: Inframince; Marcel Duchamp; Alfred North Whitehead; pragmática especulativa; valor/valoração; arte/artisticiosidade; política/o político; tempo/duração.

Abstract: Marcel Duchamp describes the infrathin as "the most minute of intervals, or the slightest of differences" (DUCHAMP apud PERLOFF, 2002, p. 101). Working through Duchamp's proposition, and taking him at his work that the infrathin cannot be defined as such - "One can only give examples of it" (DUCHAMP apud DE DUVE, 1991, p. 160) - this paper explores how the infrathin comes to expression and asks what a politics of the infrathin might look like. Key to the exploration is the question of how else value can be defined and how this rethinking of the concept of value might compose with the concept of a pragmatics of the useless.

Keywords: Infrathin; Marcel Duchamp; Alfred North Whitehead; speculative pragmatics; value/ valuation; art/artfulness; Politics/The Political; Time/Duration.

1 Versão de For a Pragmatics of the Useless, or The Value of the Infrathin; texto ainda não publicado. Tradução de André Fogliano e revisão de Francisco Trento.

2 NT: No original deste artigo a autora traduziu o termo para o inglês: infra-thin. Optamos por manter o conceito no francês, como formulado por Duchamp e retomado por Christine Greiner e Helena Katz no ensaio Visualidade e imunização: o inframince do ver/ouvir da dança. "Desenvolvido nos anos 1930 e publicado em 1945 por Marcel Duchamp (1887-1968), que foi leitor de Ciência e Hipótese, livro que Poincaré escreveu em 1905, o conceito de "inframince" refere-se a um modo de tratar as dimensões temporais e físicas, pois 'mince', em francês, refere-se ao ultrafino, ultrapequeno. "Inframince" é também o título de parte de uma coleção póstuma de notas de Duchamp publicadas por Paul Matisse" (GREINER; KATZ, 2012). 


\section{O mais ínfimo dos intervalos}

Duchamp descreve o inframince como "o mais ínfimo dos intervalos, ou a mínima das diferenças" (DUCHAMP apud PERLOFF, 2002, p. 101). ${ }^{3}$ Ele sugere que o conceito não pode ser adequadamente definido - "dele só é possível dar exemplos" (DUCHAMP apud DE DUVE, 1991, p. 160) ${ }^{4}$. As notas dos manuscritos de Duchamp apontam para algumas direções: "a quentura de um assento (que acabou de ser deixado) é inframince"; "O portão do metrô - naquele último instante em que as pessoas o atravessam / Inframince". "Calças aveludadas - o assobio produzido no roçar das pernas ao caminhar é um inframince sinalizado pela sonoridade (isso não significa um inframince sonoro)", "A diferença entre o contato / da água, do / chumbo fundido, / ou de um creme e / o das paredes do / próprio container girando em volta do líquido"... a diferença entre esses dois contatos é inframince" (DUCHAMP apud PERLOFF, 2002, p. 101). ${ }^{5}$

As notas de Duchamp tentam tatear o que permanece elusivo. A qualidade do que está entre, um intervalo que não pode ser plenamente articulado. Não é o assento que está em questão, ou mesmo a quentura no "assento (que acabou de ser deixado)", mas o que é deixado para trás. Não o assento, a qualidade de deixidade (left-ness). Não as calças aveludadas, o roçar das pernas ao caminhar e "o assobio produzido", mas o modo como a esfregação cria a qualidade de um assobiar. Não exatamente as substâncias na "diferença entre o contato da água, do chumbo fundido...", mas a qualidade dessa inter-relação.

O inframince: a potencialidade de um campo relacional incluir o que ainda não pode ser bem articulado, não obstante possa ser sentido. Inframince: estidade (this-ness), hecceidade de uma experiência irredutível à soma de seus elementos.

\section{O exemplar}

Na ausência de uma definição, o que fica em primeiro plano é a singularidade da experiência e a especificidade do exemplo. O inframince não pode ser generalizado através da experiência: ele é o que faz da experiência singularizada o que ela é, aqui, agora. Entre o acontecimento e os desdobramentos de sua narrativa, reside um inframince que jamais será totalmente capturado. "Ao tentar colocar uma superfície plana / precisamente sobre outra superfície plana, / você atravessa alguns instantes inframince (DUCHAMP apud PERLOFF, p. 101). ${ }^{6}$ Para além da captura, o inframince é uma apreensão na singularidade

3 "The most minute of intervals, or the slightest of differences". NT: Para as obras sem tradução para o português optamos por uma tradução livre nossa.

4 "One can only give examples of it".

5 "The warmth of a seat (which has just been left) is infra-thin (\#4)," "Subway gates-The people / who go through at the very last moment / Infra thin—(9 recto)," "Velvet trousers--/ their whistling sound (in walking) by/ brushing of the 2 legs is an / infra thin separation signaled /by sound. (it is not an infra thin sound) (\#9 verso)," "Difference between the contact / of water and that of/ molten lead for ex /or of cream / with the walls of its / own container moved around the liquid... this difference between two contacts is infra thin (\#14)".

6 "While trying to place 1 plane surface/ precisely on another plane surface/you pass through some infra thin moments". 
de um intervalo demasiadamente tênue para ser definido como tal, embora ele constitua a espessa textura das relações vividas.

\section{Preensão}

A preensão é uma compreensão-em-direção-a pela qual a experiência se faz sensível. O acontecimento - ou a ocasião real, nos termos de Whitehead - é arrastado para dentro da experiência, cuja força de atualização está entrelaçada com o que Whitehead nomeou os dados de uma ocasião. Esses dados não são objetos ou substâncias, mas campos relacionais em processo de análise.

O que pensar, contudo, da fração dessa compreensão que não pode ser inteiramente analisada, arrastada para a atualidade? Continua ela insistindo? O que dizer daquilo que não pode ser inteiramente capturado, muito embora produza uma diferença no acontecimento? O que dizer daquilo que não pode ser inteiramente definido por si mesmo, muito embora participe da maneira como o mundo é sentido? Como articular, na prática, a preensão com o inframince da experiência?

Whitehead tem um conceito para aquilo que não é atualizável, não obstante afete a experiência. Ele o denominou preensão negativa. Preensão negativa é o que deve ser ativamente excluído para que o acontecimento tenha consistência. Para ganhar consistência é preciso eliminação. O que não se adequar à coloração dessa experiência singular é posto em pano de fundo para que a experiência venha a ser totalmente o que é.

Todavia, eliminação é ainda participação. Excluído por necessidade daquilo que está em relevo, a preensão negativa, apesar de tudo, permanece eclipsada no limite do aparecimento, como todo pano de fundo. Como tal, não é atualizada no acontecimento, mas este não pode deixar de ser infundido naquela. Cada preensão envolve, em algum nível, o que a preensão negativa urde.

O que o inframince torna palpável é que não há ocasião a qual não traga para a frente, em algum nível, aquilo que estava no pano de fundo. $O$ inframince sensifica a tênue qualidade desse tanto-quanto. A passagem do sentado ao levantado, que deixa algo para trás, - a qualidade ininteligível não obstante sensível - carrega o fundo turbilhonado e o arrasta para dentro do intervalo da experiência vivida. Inframince.

O inframince recobre ativamente o que é percebido tendo em vista nuançar aquilo ainda não inscrito no registro do perceptível. O inframince nuança essa ininteligibilidade no inteligível, afirma a copresença da experiência fundo-figura. Sendo assim, o inframince imediatamente preende a potência do mais-que ${ }^{7}$ (more-than).

7 NT: O conceito de mais-que mobilizado pela autora é extraído da obra de Gilbert Simondon. Simondon utiliza mais-que-indivíduo, ou mais-que-humano, muito próximo do conceito de extra-ser de Deleuze, na linhagem do estoicismo antigo. 


\section{Forma subjetiva}

Na filosofia do processo, o fundamental é o movimento, ou a mudança. Para que a mudança aconteça, contudo, é preciso um momento no qual a ocasião tenha se tornado absolutamente o que ela é. Sem essa absolutidade (absolutness), não haveria diferença alguma entre este e aquele - nenhum "espaço de manobra no universo" (WHITEHEAD, 1978, p. 195). ${ }^{8}$

A forma subjetiva é a assinatura desta ocasião singular. Ela é o que imediatamente emergiu como sujeito da ocasião, um sujeito gerado do processo. Em si mesmo, o sujeito não pode mudar. No contexto desta iteração singular, ele terá sido sempre o que agora se tornou. No entanto, como enfatiza Whitehead em toda sua obra, esta atualização do isto é é efêmera, sempre no limite de perecer, ali onde a força, e não a tomada-de-forma, contribuía para os processos futuros. Se a forma subjetiva marca o limiar entre força e forma, e a divisão (schism) ativa entre o que é e o que pode vir-a-ser, a pergunta operativa é: em que medida o inatualizado atua na passagem da força para a forma? E em que nível esse pedaço do inatualizado pode alterar os futuros vir-a-ser das formas?

É justamente nesse ponto que a preensão negativa aparece. Apesar da não inclusão dentro da atual constelação do acontecimento se tornando este ou aquele, a preensão negativa de fato possui uma forma subjetiva. "A preensão negativa expressa um vínculo", escreve Whitehead (1978, p. 41). ${ }^{9}$ O vínculo "contribui com o complexo emocional, não com os dados objetivos" (WHITEHEAD, 1978, p.41). ${ }^{10} \mathrm{O}$ fato de a preensão negativa possuir formas subjetivas sugere que o inatualizado também influencia a maneira como o futuro se torna sensível.

\section{Percepção autista}

A preensão negativa é negativa apenas no sentido de eliminar um certo conjunto de dados tendo em vista permitir a consistência do primeiro plano na atualização do que vem a ser. Como Whitehead esclarece, quando este e não aquele é sentido, "aquele" não foi completamente exercido pela experiência. Ambos participam do jogo: é o tornar-se-fundo "daquele" que faz o "este" vir ao primeiro plano.

Os dois, ao mesmo tempo. Na verdade, a experiência como primeiro plano corre sempre o risco de confusão e caos. Entretanto, em certo grau, é sempre os dois ao mesmo tempo. Como os hiper-sensitivos irão atestar, a relação figura-fundo, primeiro-plano-pano-de-fundo, pode ser dolorosamente entrelaçada. Por exemplo, os autistas referem-se frequentemente à dificuldade de diferenciar um tipo de sensação ou força de uma outra, de apartar a multiplicidade de emoções do ambiente dolorosamente vivo. ${ }^{11}$

8 "Elbow room in the universe."

9 "A negative prehension expresses a bond".

10 "Adds to the emotional complex, though not to the objective data".

11 Eu explorei a noção de percepção autista através dos escritos de Tito Mukhopadhyay, Amanda Baggs, DJ Savarese, Larry Bissonnette e outros. Para uma refinada conceituação do termo e uma análise dos incisivos escritos dos autistas, ver o capítulo An ethic of language in the making, em Always more than one: invididuation's dance (2012). 
Este caso limite nos lembra que é um problema de grau. O como a preensão negativa elimina os dados é uma questão de prática, antes de qualquer outra coisa. O fim necessário não é uma análise ou eliminação absoluta, mas uma técnica que permita alcançar um grau de consistência modulável. Esta é a força do conceito de preensão negativa: a saber, dar-nos as ferramentas para que possamos considerar uma certa participação na experiência do fundo turbilhonante, uma certa ressonância vital daquilo que, sempre diferente em grau, no entanto, é eliminado da ocasião no processo de atualização. O inframince é uma técnica para fazer ressoar o inanalisável da experiência.

Se aquilo que é preendido, no acontecimento, inclui eliminação, por conseguinte, a eliminação é afirmada. A preensão negativa deve ser entendida como o negativo da imagem, não como uma negação simplesmente. É um aspecto contributivo da experiência que escapa do atual como tal, ao mesmo tempo em que afeta como ele é expressado.

O inframince acena em direção a esse corte do acontecimento, procurando um modo de tornar sensível aquilo que nunca toma forma concreta, não obstante faça toda a diferença. Por essa razão, o inframince pode ser somente exemplificado. Defini-lo seria dar-lhe a forma que lhe escapa.

O inframince: o mais elusivo dos estados, onde o que é sentido, no mais ínfimo dos intervalos, é a vital co-composição da diferença. Contraste.

O inframince: a diferenciação que marca o ritmo, ou seja, a oscilação entre o perceptível e o imperceptível sensível, no acontecimento. A estidade (this-ness), a hecceidade, dessa relação singular, percebido em duas direções, ao mesmo tempo.

O inframince: a variação da experiência vivida, no acontecimento.

\section{Valor}

Na filosofia de Whitehead, uma ocasião de experiência nunca é valorada antes do seu vir-a-ser. A experiência não possui nenhum valor inato, tampouco possui uma hierarquia de valores. O humano e o não-humano, a consciência e a não-consciência, são igualmente considerados por essa filosofia que define os corpos como uma sociedade de moléculas. A pergunta fundamental não é "o que tem valor inato?", mas "quais as condições de possibilidade para que uma transição de nível se expresse, e como isto altera a experiência vivida?".

Nos organismos de baixo grau de complexidade as transições de nível são principalmente físicas. O contraste é limitado, nestas ocasiões, a uma restrita gama de diferença, e uma quantidade muito mais elevada é eliminada da experiência daquilo que é dobrado. Nos organismos de maior complexidade, a sensação é mais nuançada, em virtude da forma subjetiva de certa ocasião ser tingida de múltiplas maneiras pelas preensões negativas que positivamente foram eliminadas. 


\section{Objetos atemporais}

Nas duas pontas do espectro, os objetos atemporais promovem o contraste. Os objetos atemporais são a pura potência de uma relação sentida. Eles dão à ocasião sua nuance. Eles são a hecceidade da qualidade diferencial do acontecimento - apenas esta qualidade do som, apenas este tom de cor, apenas esta tonalidade afetiva. A forma subjetiva de determinada ocasião sente o mundo apenas deste modo. Esta sensação, Whitehead afirma, "tem sua geração não inteiramente identificável com os meros dados. Ela se adequa aos dados, uma vez que os sente. Mas o como do sentir, apesar de pertinente aos dados, não é totalmente determinado por eles" (WHITEHEAD, 1978, p. 85). ${ }^{12}$ Por esse motivo, há sempre um empurra e puxa, na sensação, entre o ser-dado e potencialidade. O ser-dado é necessário para a ocasião afirmar-se como esta ou aquela, enquanto a potencialidade garante que o mais-que (more-than) permaneça incluído, ainda que marginalmente, nos casos dos organismos de menor complexidade.

A potência do mais-que (more-than) penetra a ocasião através do objeto atemporal. "A qualidade da sensação deve ser definida com respeito aos objetos atemporais pelos quais o sentir se reveste em sua auto-definição" (WHITEHEAD, 1978, p. 86). ${ }^{13}$ O que é sentido sempre inclui uma fração de potência especulativa, um valor indescritível.

Mesmo preendido negativamente, este valor indescritível produz uma diferença.

Somente uma seleção de objetos atemporais é sentida por um sujeito dado, e, então, desses objetos atemporais, diz-se que eles penetraram aquele sujeito. Não há motivo, no entanto, para que os objetos atemporais não sensíveis sejam negligenciáveis. Por conseguinte, cada preensão negativa tem sua forma subjetiva própria, por trivial ou vaga que seja (WHITEHEAD, 1978, p. 41). ${ }^{14}$

A potência pura pode ser relegada ao segundo plano - "as atualidades têm de ser sentidas, ao passo que as potências puras podem ser desdenhadas" (WHITEHEAD, 1978, p. 239" - mas seu chamariz permanece. O inframince é assombrado por esse chamariz.

\section{Fração especulativa}

Começar da eliminação significa nuançar o que faz diferença na experiência, apesar de sua exclusão da atualização. Se, como geralmente é o caso, o atual é a medida do valor-de-uso, poder-se-ia inferir que o que não está, de fato, incluído na ocasião é sem valor.

12 "Has an origination not wholly traceable to the mere data. It conforms to the data, in that it feels the data. But the how of feeling, though it is germane to the data, is not fully determined by the data".

13 "The quality of feeling has to be definite in respect to the eternal objects with which feeling clothes itself in its self-definition".

14 "Only a selection of eternal objects are 'felt' by a given subject, and these eternal objects are then said to have 'ingression' in that subject. But those eternal objects which are not felt are not therefore negligible. For each negative prehension has its own subjective form, however trivial and faint". 
Isso porque o inatualizado não somente é indiscernível como tal, mas é incomensurável, mesmo depois do acontecido. Entretanto, é precisamente esta inefabilidade, no cerne do acontecimento, que confere valor à experiência. $O$ valor dessa fração especulativa da experiência reside no fato de que ela dá o tom do acontecimento, ela torna sensível a discernibilidade da experiência, para além de uma definição.

Esta pode ser a primeira proposição para uma pragmática da inutilidade: quando a experiência conecta-se com o inframince, o que é afirmado é um outro modo de pensar o valor. Para além do valor-de-uso, não a valoração do que está dado, mas a capacidade de transvaloração passível de performar uma passagem no cerne mesmo da incompleição (incompletion) do processo, da indeterminação inerente do processo. Numa perspectiva nitzscheana, valor, aqui, deriva do in-act $t^{15}$ do processo mesmo de afirmação da diferença: "a criação toma o lugar do próprio conhecimento, a afirmação, o lugar de todas as negações conhecidas" (DELEUZE, 1976, p. 80). Uma pragmática da inutilidade celebra essa fração da experiência que é afirmada não pelo que ela é, mas pelo modo como ela afeta a experiência na prática.

Uma pragmática da inutilidade é uma pragmática no sentido de estar plenamente orientada para como o acontecimento se efetivará. Esta instância do inframince. Estas condições para ativação deste intervalo de experiência. $\mathrm{O}$ acontecimento não pode ser generalizado através de repetições. Ele é sempre exemplificado, sempre pragmática especulativa.

Uma pragmática da inutilidade é especulativa no sentido de estar aberta à transformação, pela força potencial daquilo que atravessa o acontecimento, mesmo quando não há uma realização completa. O potencial atravessa pela natureza assim-comoeste do acontecimento, fazendo-o reverberar. $\mathrm{O}$ inframince é sentido nessa reverberação, potencialmente singular.

\section{Potencialmente singularizante}

Todas as ocasiões atuais carregam esta qualidade do inframince. Se, por um lado, o acontecimento é singularmente o que é - esta superfície plana -, por outro, o acontecimento inclui, também, no movimento de reverberação da singularidade, uma abertura à diferença. A força potencialmente singularizante do inframince advém de sua capacidade de ser tanto-quanto.

Persistir no intervalo tanto-quanto é sentir o dobrar-se do tempo no acontecimento. Significa sentir tanto a absoluta assinatura-do-tempo - o pragmatismo do que acontece,

15 NT: Preferimos manter o neologismo in-act na língua nativa, ao invés de vertê-lo para em-ato, em-ação, na-prática ou quetais. No inglês preservamos a ambivalência do jogo de palavras da autora: qualificar a ação, a prática em-ato, bem como o inact, inativo, inatividade. Essa ambivalência abre um duplo e paradoxal entendimento: por um lado, entendimento da experiência valorativa inerente do ato, do ato em si mesmo, no acontecimento; por outro, entendimento de que o processo de atualização e valoração é um ato inativo, um gesto, ou seja, não intencional, não voluntarioso, não passa pela ordem da vontade ou da consciência egóica ou individual, do cogito, mas da necessidade mesma de sua natureza material constitutiva. 
aqui, agora - quanto a potencial capacidade do acontecimento fazer uma diferença. O fazer de uma diferença é sempre, também, o fazer de um tempo. O que é singularmente potencializado pelo inframince é um acontecimento-tempo, tempo sentido em sua qualidade diferenciante, tempo menos medido que dobrado.

O que pensar, então, do fato que "a ocasião não tolera qualquer adição?" (WHITEHEAD, 1978, p. 45). ${ }^{16}$ O que dizer da afirmação de Whitehead de que "uma mão extra de vermelho não constitui uma mera adição; altera a composição inteira" (WHITEHEAD, 1978, p. 45) ${ }^{17}$ ? E da necessidade do acontecimento eliminar aquilo que não lhe é adequado?

O inframince corta através dessa necessidade, fatiando a ocasião tal que distorce sua perspectiva de conformidade. Ser-dado e potencialidade sempre operam juntos "ser-dado refere-se à potencialidade, potencialidade ao ser-dado" (WHITEHEAD, 1978, p. 45). ${ }^{18}$ Uma complexidade de sensações é realçada na diferenciação dessa sobreposição. Talvez isso seja o que pode a arte efetuar.

\section{Transversalidade}

O inframince é transversal. Não pode ser pensado como um estado. Ele é um fazersentir de uma distorção momentânea da experiência em seu movimento. O inframince sente a experiência de tal modo que nuança o fundo da ocasião e lhe permite dançar com a figura. Cria as condições para enfatizar o que o sentir não sentiu. Dá consistência à agitação, àquilo que mal é registrado, se registrado de alguma forma. "A separação do inframince entre/o barulho de detonação de uma pistola / (muito próxima) e a aparição do furo do projétil no alvo..." (DUCHAMP apud PERLOFF, p. 101). ${ }^{19}$ "A separação do inframince opera no seu máximo quando distingue o mesmo do mesmo" (DE DUVE, 1991, p. 160). ${ }^{20}$

\section{Dupla articulação}

Distinguir o mesmo do mesmo, na duração do inframince, ainda não explica como toda experiência é ativamente engajada em uma dupla articulação. O atual está sempre repleto de virtual, individuação de pré-individual, preensão com o que é preendido negativamente. Aquela mão extra de fato faz uma diferença: cria um mundo novo. O inframince torna sensível como esses dois mundos coexistem, apesar de sua brevidade.

\section{Duração}

Essa coexistência não é definível, em larga medida, por conta do desafio de pensar a duração do tempo. É difícil conceber duas temporalidades juntas no acontecimento,

16 "Intoleran[ce] of any addition".

17 "[A]n extra patch of red does not constitute a mere addition; it alters the whole balance"

18 "'Givenness' refers to 'potentiality,' and 'potentiality' to 'givenness"”.

19 "Infra thin separation between / the detonation noise of a gun / (very close) and the apparition of the bullet/ hole in the target...".

20 "The inframince separation is working at its maximum when it distinguishes the same from the same". 
uma vez que a linguagem desdobra um sujeito, um substantivo, um verbo, por vez. A arte pode realizar isso, mas somente quando resiste a definir-se, unicamente, segundo a forma. O que a arte pode fazer é ativar o inframince de uma força potencializante. A força própria da arte é a capacidade de compor mundos que ativam uma espécie de acontecimentotempo geológico - uma camada, um composto de tempo-sentido. Em outro trabalho, eu me referi a isso como a arte do tempo, a capacidade da arte de tornar sensível, através da força da intuição, a complexidade do tempo.

"Apenas toque. Ao tentar colocar uma superfície plana / precisamente sobre outra superfície plana, / você passa por uns instantes de inframince" (DUCHAMP apud PERLOFF, p. 102). Quando escreve isso, Duchamp indica que existe um tocar na arte do tempo. Há algo sentido - "você passa por uns instantes de inframice" - que não pode ser propriamente atribuído à percepção. Isso porque não é "você" quem passa por algo, mas o plano que sente a si mesmo na passagem, que sente a co-composição do campo relacional com o plano adjacente, que sente as camadas de duração pela qual a distinção tanto de sua planidade (plane-ness) quanto de sua adjacência não é possível.

A arte pode mover-nos por entre os planos de duração, tornando-os intuitivamente sensíveis de tal forma que uma qualidade de existência é momentaneamente roçada. Esse roçar nada tem de metamorfose: é uma experiência vital. Uma abordagem mimética dessa dinâmica falhará. O inframince deve sempre ser ativado novamente. De uma vez por todas: ele jamais pode ser reproduzido.

\section{Uma pragmática da inutilidade}

Emerge uma segunda proposição para uma pragmática da inutilidade: o valor também precisa ser ativado novamente, a cada vez. A arte verdadeiramente engajada com aquilo que ainda não encontrou sua forma própria intuitivamente se afasta da reprodução mimética. Para ser artisticiosa (to be artful) - ativamente conectada à diferenciação da experiência, na prática - não deve nunca buscar, de antemão, a definição de seu valor, nem nunca reclamar saber como o inframince se fará sensível. A assombração da preensão negativa deve continuar um assombro.

Tomar-forma é o risco da arte. Não há como escapar à tomada-de-forma. A experiência não se faria cognoscível sem isso. A tomada-de-forma, contudo, não deve submeter-se à categoria da pré-valoração. A experiência não deve saber a priori o que pode sua formação.

\section{A quarta dimensão}

Para Duchamp, o inframince aparece como um modo de se pensar a respeito do tempo que ultrapasse a segunda, em direção à terceira e até mesmo à quarta dimensão. 
A preocupação fundamental da arte do tempo é sua capacidade em tornar sensível a não-linearidade temporal da preensão negativa. "O possível implica devir - a passagem de um ao outro acontece no inframince" ${ }^{21}$

Tornar sensível a quarta dimensão significa entender a dobra como a impossibilidade de medição do tempo. Aqui, no dobramento da experiência quadruplicando-se em si mesmo, o inframince toca a superfície da perceptibilidade. O inframince de Duchamp deixa claro a necessidade de um conceito que expresse a imperceptibilidade no perceptível.

Duas formas talhadas / no mesmo molde diferem / uma da outra / por uma quantidade separável de inframince - Todos os "idênticos", tão / idênticos quanto podem ser (e / quanto mais idênticos são), / deslocam-se em direção a esta / separável diferença de inframince. Dois homens não são / um exemplo de identicabilidade, /ao contrário, / afastam-se de uma diferença determinável de inframince (apud PERLOFF, p. 101).22

\section{O diferencial}

O imperceptível no perceptível é o diferencial da experiência. O inframince mobiliza o diferencial, aquela parte da percepção na borda da perceptibilidade, em que o que é mal sentido (ou o que não é nem sentido) produz uma diferença. Duas formas talhadas no mesmo molde carregam a força dessa diferença, apesar de aparentarem uma mesmidade; os idênticos persistem ao permanecerem qualitativamente mais-que (morethan) a identicabilidade. Essa diferença qualitativa, cuja perceptibilidade frequentemente Ihe escapa, é o mais-que (more-than) da experiência in-forming ${ }^{23}$; é a total potência do ser-dado no extremo da borda dobrando sobre si mesmo. "A separação do inframince opera no seu máximo quando distingue o mesmo do mesmo".

\section{O extemporâneo}

Henri Focillon descreve essa borda da perceptibilidade na experiência do inframince nos termos de uma extemporaneidade (apud DAVILA, 2010, p. 13-14). A extemporaneidade do inframince realça o que Whitehead nomeou "uma mútua sensibilidade de sensações"

21 "The possible implies becoming - the passage from one to the other takes place in the infrathin". Disponível em: http://epc.buffalo.edu/authors/perloff/21/21_duchamp.pdf. Acesso em: 20 dez. 2014.

22 " 2 forms cast in / the same mold differ / from each other/ by an infra thin separative /amount - All 'identicals' as / identical as they may be, (and / the more identical they are)/ move toward this / infra thin separative difference. 'Two men are not / an example of identicality / and to the contrary / move away / from a determinable / infra thin difference-but".

23 NT: a autora utiliza o neologismo in-forming que tem um sentido duplo. Funciona, por um lado, como formação, $\mathrm{o}$ ato de ganhar forma, e, por outro, como o seu inverso informing significando informar, cujo conceito varia enormemente a depender da perspectiva científica ou teórica adotada. Preferimos manter o termo na língua nativa do que vertê-lo para o português em-formação, pois haveria o risco de perder sua força paradoxal de significação. 
(1978, p. 221). Essa sensibilidade mútua inclui a contribuição do que foi eliminado do real. Ela inclui a forma subjetiva da preensão negativa.

\begin{abstract}
A preensão negativa tem suas formas subjetivas próprias, as quais colaboram para o processo. A sensação carrega consigo as cicatrizes de sua geração; recorda como uma emoção subjetiva luta pela existência; retém a impressão do que poderia ter sido mas não é. Por esse motivo, o que uma entidade real excluiu como o dado de uma sensação pode ser ainda uma importante parte de seu equipamento. O real não se reduz a um mero fato divorciado do potencial (WHITEHEAD, 1978, p. 226-227). ${ }^{24}$
\end{abstract}

Sentir, para Whitehead, é o complexo da experiência: a filosofia do processo não é uma analítica da razão pura, mas da sensação pura. "O sentir é inseparável da finalidade a que aspira; essa finalidade é aquele-que-sente. A sensação mira aquele-que-sente, sua causa final. As sensações são o que são para que os seus sujeitos sejam o que são" (WHITEHEAD, 1978, p. 222). ${ }^{25}$ O acontecimento é sua tonalidade afetiva. Uma intempestividade é vivida neste interstício afetivo onde o sentir e aquele-que-sente vivem sua mútua inclusão no acontecimento. Frequentemente, nós os separamos como se um viesse antes do outro, em uma hierarquia de valores: a crítica da razão pura prevalece se situarmos aquele-quesente fora do acontecimento, julgando a ocasião de seu exterior. A filosofia do processo não aceita essa perspectiva. Não há fora da sensação. Como a ocasião foi sentida é a experiência, é da sua razão tornar-se o que é. ${ }^{26} \mathrm{O}$ sujeito do acontecimento - seu superjecto é a intempestividade da sensação dobrando-se sobre si mesma. Esse dobrar cria as nuances da experiência às quais Duchamp acena com seu conceito de inframince.

A sensibilidade mútua da sensação realça a dobra entre o sentir e aquele-quesente, trazendo à tona a tonalidade afetiva do acontecimento-tempo. O inframince é essa compreensão-em-direção-a, essa diferenciação do mesmo na extemporaneidade do intervalo vivido entre o sentir e aquele-que-sente. O inframince dá a mais breve consistência para esse cluster experiencial.

\title{
Cluster experiencial
}

O cluster experiencial, no qual o sentir e aquilo-que-foi-sentido são a mesma coisa, como toda ocasião, "só pode ser sentido uma vez" (WHITEHEAD, 1978, 231)27.

24 "The negative prehensions have their own subjective forms which they contribute to the process. A feeling bears on itself the scars of its birth; it recollects as a subjective emotion its struggle for existence; it retains the impress of what it might have been, but is not. It is for this reason that what an actual entity has avoided as a datum for feeling may yet be an important part of its equipment. The actual cannot be reduced to mere matter of fact in divorce from the potential".

25 "The feelings are inseparable from the end at which they aim; and this end is the feeler. The feelings aim at the feeler, as their final cause. The feelings are what they are in order that their subject may be what it is".

26 Desenvolvo mais demoradamente o conceito de razão em Whitehead (seguindo suas intuições contidas em A função da razão) no texto Against method em Non-representational methodologies (2015).

27 "Can only be felt once". 
Essa sua natureza extemporânea reside na combinação de sua singular unicidade com a sua mise-en-abyme. Desse modo, o inframince torna sensível a agitação do tempo no agir, no sentir, em que o tempo é imediatamente aqui-agora e quase-lá. Duchamp parece sugerir que este é o trabalho da arte, a saber, criar as condições pelas quais o tempo do acontecimento, em toda sua agitação extemporânea, pode ganhar expressão. Criar as condições para uma expressão material de duração no limite.

Isso implica a invenção de técnicas para ativação do cluster experiencial, cujo tempo é o do acontecimento. Talvez, seja este o sentido da proposição de Robert Smithson ao afirmar que o artista cria no interstício no qual futuros longínquos encontram passados longínquos. Ou quando Duchamp escreve que "em cada fração de duração são reproduzidas todas as frações futuras e anteriores" (DUCHAMP apud DAVILA, 2010, p. 14).28

\section{Um pedaço seu}

Quando a experiência devém extemporânea, quando o acontecimento-tempo apropria-se da experiência, fica evidente como o sujeito não reside fora do processo, olhando para dentro. Francis Alys argumenta que "depois de um tempo... você começa a oscilar em você mesmo. Você esquece da mecânica da peça e adentra esta espécie de espaço dormente. Você apenas assiste e é, aí, afinal, que acede àquela diferente percepção do tempo, qual seja, espaçada entre dois mundos." ${ }^{\prime 29}$

Quando se trata, no acontecimento, do que sentiu aquele-que-sente, "você", de fato, apenas assistiu. $\mathrm{O}$ inframince da experiência carrega, em seu fazer próprio, o você que você está em vias de tornar-se. Por essa razão, ainda que o artista seja capaz de criar as condições para o inframince, é o inframince que, em última análise, tudo arrasta. Robert Irwin defende que

a função do artista é, em certo sentido, diagnosticar continuamente o que lá se passa... Logo, o valor não é neutro; uma vez negociado, ele advém um pedaço seu, finalmente. Isso pode reconstruir como você pratica, ou como vocês se movimentam pelo mundo. Enfim, isso implica a transformação das estruturas a sua volta. No entanto, é um projeto de longo prazo. A mudança real que advém das sensações e dos valores tem de ser semeada para que, então, comece a atuar nas coisas - em você, posteriormente em como você toma decisões e julgamentos e, afinal, em como constrói o mundo (IRWIN, 2007, p. 56). ${ }^{30}$

28 "In each fraction of duration are reproduced all fractions future and anterior".

29 "After a while, [...] you start oscillating yourself. You forget about the mechanics of the piece and you are entering this kind of lullaby space. You just take a back seat and that is where eventually you accede to that different time perception, which is in between two worlds of space." Disponível em: http://www.siobhandavies.com/ conversations/alys/transcript.php. Acesso em: 23 dez. 2014.

30 "The role of artists is, in a sense, to continually examine what's going on there (...)And so value is not neutral; once negotiated, it ultimately becomes a piece of you. It can reconstruct how you practice, or how you move in the world. In time, that has the implication of changing the structures around you. But it's a long-term project. The real change that comes from feelings and values has to be seeded, in a sense, and then it begins to act on things —on you, and then on how you make decisions and judgments, and therefore on how you construct the world". 
No acontecimento, o trabalho do artista torna-se urgentemente sintonizado com as nuances ativadas, na prática, pelo inframince da experiência.

\section{Consciência}

É comum privilegiarmos um processo consciente em detrimento de um nãoconsciente. Whitehead insiste: o modo como o acontecimento sente seu potencial não está necessariamente relacionado com a consciência. A consciência é tão meramente um aspecto da capacidade da ocasião acontecimentar-se.

O inframince não depende da consciência para tornar-se expressão. E, apesar disso, ele atinge a borda de uma sensibilização na qual consciente e não-consciente se co-compõem. Nesse ponto, onde graus e escalas de sensação atuam, estamos no meio de uma percepção autista, a ativa disposição da experiência de bordar-se em si mesmo. Eliminação está incluída, as tendências extemporâneas do não-consciente são sentidas diretamente.

Entre graus de sensação, neste energizado interstício, o que é percebido é a sensação de contraste. O diferencial está vivo, na borda da experiência in-forming. Quando Irwin ou Alys falam sobre o sensível da arte movendo alguém, eles concebem essa experiência desde essa perspectiva extrema. O que pode a arte é criar as condições de um modo outro de percepção. "Na realidade, eu penso que nesse momento nos confrontamos com o como passar do modelo tridimensional para o quadridimensional. Como fazer isso, verdadeiramente? Como lidar com esse modo de ver quadridimensional? E qual tipo de prática ou ordem social resultará disso?" (IRWIN, 2007, p. 58). ${ }^{31}$ Modos outros de perceber criam modos outros de viver.

\section{Quarta-pessoa do singular}

Poderia o inframince propor um modo de ver quadridimensional? Se possível fosse, isso suscitaria o que Deleuze chamou de "quarta-pessoa do singular"? A quartapessoa do singular, o impessoal "il pleut", no francês, produz uma ação impessoal, no acontecimento. Isso não é parecido com a maneira como o inframince coloca em primeiro plano o tempo em sua multiplicação em camadas? Não o tempo do sujeito da consciência externa, fazendo-se visível, mas aquele da co-composição do sentir e daqueleque-sente na experiência vivenciada? A quarta dimensão, não como 1+3, mas como n+1 "os muitos devêm um, e são incrementados pelo um" (WHITEHEAD, 1978, p. 21). ${ }^{32}$ Tempo se dobrando, se percebendo.

\footnotetext{
31 "Actually I think that right now we're wrestling with how to go from a three-dimensional model to a fourdimensional one. How do you actually do that? How do you deal with a four-dimensional way of seeing? And what kind of social practice or order will result?".

32 "The many become one, and are increased by one".
} 


\section{A tensão entre coisas}

Doug Wheeler escreve: "como artista, eu comecei a brincar com isto: não olhar para as coisas, mas para a tensão entre as coisas". ${ }^{33} \mathrm{~A}$ tensão entre as coisas é o $\mathrm{n}+1$ do inframince: a imensurável força da diferença que cria o interlúdio no tempo do acontecimento. É, aqui, na força da dobra do tempo, onde o valor-de-uso ainda não foi determinado e a pragmática está no máximo de sua especulação, que o que pode a arte é palpável.

\section{$\mathrm{O}$ incremento criativo}

Quando Whitehead desenvolve a ideia de incremento criativo como o impulso do que pode um acontecimento, no seu extremo máximo de inventividade, ele se refere, em um certo sentido, à força da arte do tempo. Não se trata da criação de uma obra de arte, mas de uma maneira de falar sobre o chamariz para a sensação, do diferencial da experiência em seu processo. Na filosofia do processo, esse diferencial é nomeado contraste. O que pode a arte, no ápice de sua inutilidade pragmática, é tornar sensível, no acontecimento, a força diferencial do tempo, a fração, no acontecimento, que é contraste. Wheeler, ao falar da "tensão entre as coisas", não a entende como um espaço entre objetos, mas como a atividade extemporânea do campo relacional. Essa atividade extemporânea está repleta de germes de contraste, o que torna complicada a separação entre o sentir e aquele-que-sente.

\section{Contraste}

Para Whitehead, contraste vem sempre de par com a sensação conceitual. Uma diferença qualitativa, no acontecimento, é uma sensação conceitual. A respeito do apetite do acontecimento em devir, ou do que Whitehead denomina concrescência:

Em cada concrescência há um duplo aspecto do impulso criativo. De um lado, a geração de simples sensações causais; de outro, a das sensações conceituais. Esses aspectos contrastantes receberão os nomes de polos físicos e mentais de uma entidade atual. Nenhuma entidade atual é privada de ambos os polos; muito embora a importância relativa deles difira em diferentes entidades atuais (WHITEHEAD, 1978, p. 239). ${ }^{34}$

33 "That's what I started playing with as an artist: not looking at things but the tension in between things". Disponível em: http://articles.latimes.com/2011/sep/18/entertainment/la-ca-pst-hugh-davies-and-doug-wheeler-20110918. Acesso em: 20 dez. 2014.

34 "In each concrescence there is a twofold aspect of the creative urge. In one aspect there is the origination of simple causal feelings; and in the other aspect there is the origination of conceptual feelings. These contrasted aspects will be called the physical and the mental poles of an actual entity. No actual entity is devoid of either pole; though their relative importance differs in different actual entities". 
A sensação conceitual faz com que a diferença qualitativa seja sentida, exatamente, porque é capaz de reter aquilo que resta, de fato, excluído, não obstante incluído, imanentemente, como contraste.

A "tensão entre as coisas" não se refere ao que é atualmente percebido. Trata-se, isto sim, de pôr em relevo a divisão (schism) da percepção. A tensão entre as coisas é o campo relacional retendo a diferença, no acontecimento. "A diferença entre o contato / da água, do / chumbo fundido, / ou de um creme e / o das paredes do / próprio container girando em volta do líquido". Inframince não é uma medida, é uma sensação. Duchamp sentencia: "Eu escolho deliberadamente a palavra mince que é uma palavra humana e afetiva e não uma cirúrgica medida de laboratório". ${ }^{35}$ A preensão negativa anima o campo relacional, agitando as bordas daquilo que traz consigo em ressonância diferencial. A sensação conceitual produz uma dissonância qualitativa na agitação criativa.

\section{Sensação conceitual}

As sensações conceituais valoram o acontecimento: "introduzem o fator de "valoração", isto é, "valoração positiva" ou "valoração negativa" (WHITEHEAD, 1978, p. 247). ${ }^{36}$ Essa valoração, de acordo com Whitehead, abre o acontecimento para uma "criação propositiva". A introdução da criação propositiva acontece na extemporaneidade da agitação criativa da tensão. "Cada entidade atual está "no tempo" pelo que concerne seu polo físico, e está "fora do tempo" pelo que concerne seu polo mental. É a união de dois mundos: nomeadamente, o mundo temporal e o mundo de valoração autônoma" (WHITEHEAD, 1978, p. 248). ${ }^{37}$ A sensação conceitual, o polo mental do acontecimento, dá textura àquilo que não é propriamente atualizado, não obstante sentido no dobrar do tempo.

Devemos recordar, uma vez mais, que o fato de afirmarmos que a sensação conceitual valora o acontecimento não significa que o que é atualizado determine o valor. É precisamente a possibilidade de determinação daquilo que não pode ser dito plenamente que move o acontecimento em direção ao seu incremento criativo. O valor não pode ser conhecido em si, apenas pode ser experimentado nas bordas de um processo demasiado extemporâneo à medida.

\section{O não-objeto}

Em ensaio intitulado What is art and where it belongs, Paul Chan argumenta: "a arte usa as coisas para fazer sua presença sensível. Mas a arte não é em si mesma uma coisa.

35 "I purposefully chose the word thin that is a human and affective word and not a precise laboratory measure," Disponível em: http://ppetiot2.free.fr/SADT_Duchamp_Matta/01_WebPages/SADTDuchampMatta_020c.htm. Acesso em: 1 dez. 2014.

36 "Introduce the factor of 'valuation,' that is, 'valuation up,' or 'valuation down'".

37 "Every actual entity is 'in time' so far as its physical pole is concerned, and is 'out of time' so far as its mental pole is concerned. It is the union of two worlds, namely, the temporal world, and the world of autonomous valuation". 
Em outras palavras, arte é mais e menos que uma coisa. E é esta expressão simultânea de uma mais-dade (more-ness) e uma menos-dade (less-ness) que produz o que produziu arte" ${ }^{\prime 3}{ }^{38}$ O que faz da arte arte não é sua capacidade de devir-objeto, mas o modo como a arte torna sensível a extemporaneidade das tensões ativas no campo relacional por ela engendrado.

O que a arte acaba por expressar é a irreconciliável tensão que resulta do fazer algo, na medida em que intencionalmente permite que os materiais e os elementos que efetivam aquele algo transformem o fazer na mente ... antes mesmo de se tornar algo radicalmente singular, algo não derivado totalmente da mente que o produziu nem da matéria do qual foi produzido. É nesse ponto que a arte incompleta-se, e aparece (CHAN, 2009). ${ }^{39}$

A finalidade da arte não é a tomada-de-forma, mas o seu próprio processo de incompleição (incompletion). É esse o seu valor, ela pode ser apenas sentida e não definida.

Ao ativar o contraste, o que pode a arte é introduzir a incompleição (incompletion) na força da forma. Isso, como desenvolvi em outro trabalho, é a gestualidade menor que dá à arte sua artisticidade (artful). ${ }^{40}$ Ferreira Gullar, em seu esforço para articular a força da forma, propôs o conceito de não-objeto, diretamente influenciado pelo trabalho de Lygia Clark e Hélio Oiticica, entre outros. Para Gullar, o não-objeto é definido "como um quasi-corpus, isto é, como um ser cuja realidade não se esgota nas relações externas de seus elementos; um ser que, embora decomponível em partes pela análise, apenas se dá plenamente à abordagem direta, fenomenológica"41 (GULLAR apud AMOR, 2010, p. 28). Gullar estabelece que o não-objeto não é uma representação, mas uma presentação.

Para ele, o fundamental era encontrar um vocabulário adequado para o que ele percebeu ser a principal transição, em meados do século XX, em artistas como Clark e Oiticica, em direção a uma outra forma de trabalhar a materialidade. O não-objeto "irrompe de dentro para fora, da não-significação para a significação" (1959, p. 19). Ele é "pura aparência", "puro fenômeno", "sem categorizações artísticas pré-concebidas, sem consciência refletida, mas, antes, apenas com os sentidos".

38 "Art uses things to make its presence felt. But art is not itself a thing. In other words, art is more and less than a thing. And it is this simultaneous expression of more-ness and less-ness that makes what is made art". Disponível em: http://www.e-flux.com/journal/what-art-is-and-where-it-belongs/. Acesso em: 20 dez. 2014.

39 "What art ends up expressing is the irreconcilable tension that results from making something, while intentionally allowing the materials and things that make up that something to change the making in mind [...], until it becomes something radically singular, something neither wholly of the mind that made it, nor fully the matter from which it was made. It is here that art incompletes itself, and appears". Disponível em: http://www.e-flux. com/journal/what-art-is-and-where-it-belongs/. Acesso em: 20 dez. 2014.

40 Ver, por exemplo, Artfulness em The nonhuman turn (2015) e Wheather patterns, or how minor gestures entertain the environment em Complex ubiquity effects: individuating, situating, evetualizing (2014).

41 NT: para as citações de autores nacionais optamos pela versão do texto original em língua portuguesa. 


\section{O objeto relacional}

O léxico do não-objeto não é, entretanto, plenamente suficiente para o trabalho que Lygia Clark desenvolve. E, apesar de vista por Gullar como precursora do não-objeto, ela se distancia do conceito e propõe outro, o de objeto relacional ${ }^{42}$.

Não é mais o problema de sentir a poética através de uma forma. A estrutura aí só existe como um suporte para o gesto expressivo, corte, e depois de concluído, não tem nada a ver com a obra de arte tradicional. É o estado de "arte sem arte" (...) O artista aí dando esse tipo de ideia dá na realidade este "vazio-pleno" em que todas as potencialidade da opção que vem através do ato tem lugar (CLARK apud ROLNIK, 1999) ${ }^{43}$.

A diferença entre o objeto relacional e o não-objeto é de ênfase. O objeto relacional prioriza, não o fenômeno, mas a relação. Apesar do forte interesse no fenômeno, no mundo sensual, o que move a prática de Clark é a experiência vivida da tensão, no acontecimento. A abordagem não é fenomenológica, mas relacional. É ativada no inframince do que Whitehead denomina percepção não-sensual: a percepção direta da agitação do tempo, no acontecimento. Pela ativação do inframince da experiência em ato, o objeto relacional potencializa a tensão na qual aquele-que-sente e o sentir estão na mais intensa diferenciação. Torna sensível o contraste do acontecimento. Sendo assim, ele cria as condições para as várias sensações conceituais que possibilitam o acontecimento expressar sua qualidade de mais-que (more-than), sua força diferencial.

\section{O valor do inframince}

A força diferencial é repleta de potencial. O que pode a arte é tornar esse potencial sensível. Chan escreve:

Ao contrário de coisas, arte molda matéria - dá substância à realidade material sem jamais dominá-la. Toda matéria absorve as múltiplas forças que influenciaram o modo como veio-a-ser, bem como os usos e valores incrementados - além de emanar a presença dessa história e seus muitos significados desde dentro. Em certo aspecto, forma é apenas outra palavra para o conteúdo sedimentado latente em toda matéria. A arte é feita com sensibilidade e com consciência desse conteúdo. E tanto mais seu fazer se atenua tanto mais a arte se liga à maneira como esse conteúdo já determina a realidade de como a matéria existe no mundo (CHAN, 2009). ${ }^{44}$

42 Para um aprofundamento nesse conceito e em como ele se distancia do não-objeto de Gullar, ver o ensaio de Suely Rolnik: Molda-se uma alma contemporânea: o vazio-pleno de Lygia Clark. Disponível em: http://www. pucsp.br/nucleodesubjetividade/Textos/SUELY/Molda.pdf

43 Manuscrito s.d., provavelmente de 1963-64, Arquivo L. Clark

44 "Unlike things, art shapes matter-which gives substance to material reality - without ever dominating it. All matter absorbs the manifold forces that have influenced how it came to be, and the uses and values it has accrued - and emanates the presence of this history and its many meanings from within. In a sense, form is just another word for the sedimented content that smolders in all matter. Art is made with sensitivity to and awareness of this content. And the more the making becomes attenuated, the more art binds itself to the way this content already determines the reality of how matter exists in the world". Disponível em: http://www.e-flux. com/journal/what-art-is-and-where-it-belongs/. Acesso em: 20 dez. 2014. 
O valor da experiência reside na sensibilidade que leva a arte a extrair forma das tendências da matéria. A valoração envolve uma tomada de decisão imanente ao acontecimento. Não há objeto relacional plenamente operativo o qual não crie um corte no processo: um objeto é relacional em virtude de sua capacidade para ativar o campo de tal maneira que certas qualidades sobressaem mais que outras. O modo como um contraste se faz sensível é precisamente o que dá à arte artisticidade (artful).

Essa artisticidade (artful) cria campos de relação pelos quais novos modos de encontro são inventados. Tais modos inframince de encontro propõem novas maneiras de tomar o tempo, de fazer o tempo. Isso só acontece se o que vem ao primeiro plano, enquanto arte, não é o seu valor-de-uso, não é sua coisidade (thing-ness), e, talvez mais precisamente, não é o seu valor-de-troca. A arte não tem valor inato. Não é qualquer-coisa (something). Não pode ser generalizada em uma neutralização da experiência na qual aquele-quesente é amputado da sensação. A arte é exemplificada, no acontecimento, onde sensação e aquele-que-sente são diferencialmente os mesmos.

Arte é a capacidade de mobilizar diferenças no acontecimento, capacidade de fazer sensível a força da forma que desfaz aquilo que prende a arte ao seu próprio objeto, frequentemente visto como sua representação. Uma pragmática da inutilidade assume isso como sua terceira proposição: o que pode a arte excede, sempre, o objeto que deixa para trás. Uma pragmática da inutilidade: o valor não reside na forma, mas no inframince da incompleição (incompletion) da forma.

Tradução de André Fogliano e revisão de Francisco Trento.

Erin Manning é artista e professora titular de filosofia e arte relacional da Concordia University, Montreal, Canadá, onde também dirige o Senselab.

erin.manning@concordia.ca

\section{Referências}

ALYS, Francys; DAVIES, Siobhan. Conversations. Disponível em: http://www.siobhandavies.com/ conversations/alys/transcript.php. Acesso em: 23 dez. 2014.

AMOR, Monica. From work to frame, in between, and beyond: Lygia Clark and Helio Oiticica. In: Grey room 38. Massachusetts: MIT Press, 2010.

ASBURY, Michael. Neoconcretism and minimalism: on Ferreira Gullars theory of the non-object. In: Cosmopolitan modernisms. Massachusets: MIT Press, 2005.

BEST, Sue. Lygia Clark (1920-1988) bodily sensation and affect: expression as communion. In: Australian and New Zealand journal of Art, Vol. 6/7. New York: Routledge, 2006. 
CHAN, Paul. What art is and where it belongs. Disponível em: http://www.e-flux.com/journal/whatart-is-and-where-it-belongs/. Acesso em: 20 dez. 2014.

DAVILA, Thierry. De l'inframince: brève histoire de l'imperceptible de Marcel Duchamp à nos jours, Paris: Edition du regard, 2010.

DE DUVE, Thierry. The definitely unfinished Marcel Duchamp. Massachusets: MIT Press, 1991.

DELEUZE, Gilles. Nietzsche and philosophy. New York: Columbia University Press, 1986. [Nietzsche e a filosofia. Rio de Janeiro: Editora Rio, 1976].

DUCHAMP, Marcel. Le possible est un inframince. Disponível em: https://www.centrepompidou.fr/ cpv/resource/cBAg7j9/rEnGq9p. Acesso em: 1 dez. 2014.

GULLAR, Ferreira. Dialogue on the non-object. Disponível em: http://www.jenmazza.com/site/ index.php/archive/dialog-on-the-non-object/3321/. Acesso em: 20 dez. 2014. [Teoria do nãoobjeto. Disponível em: http://icaadocs.mfah.org/icaadocs/ELARCHIVO/RegistroCompleto/tabid/99/ doc/1091374/language/es-MX/Default.aspx]

IRWIN, Robert; ELIASSON, Olafur. A conversation. In: Take your time: Olafur Eliasson. Madeleine Grynsztejn (org.). Londres: Thames \& Hudson, 2007.

MANNING, Erin. Artfulness. In: The nonhuman turn. GRUSIN, Richard. (Org). Minneapolis: Minnesota UP, 2014.

Weather patterns, or how minor gestures entertain the environment. In: Complex ubiquity effects: individuating, situating, eventualizing. EKMAN, Ulrick; BOLTER, Jay David; DIAZ, Lily; SONDERGAARD, Morten; ENGBERG, Maria. New York: Routledge, 2014.

Against method. In: Non-representational methodologies. VANNINI, Phillip (Org). New York: Routledge, 2014.

Always more than one: individuation's dance. Durham: Duke UP, 2012.

MARTINS, Sergio Bruno. Phenomenological openness. In: Third text. Vol. 26/1. New York: Routledge, 2012.

OBALK, Hector. The unfindable readymade. Disponível em: http://www.toutfait.com/issues/issue_2/ Articles/obalk.html. Acesso em: 1 dez. 2014.

PERLOFF, Marjorie. 21st-century modernism: the "new" poetics. Oxford: Wiley-Blackwell, 2002.

ROLNIK, Suely. Molding a contemporary soul: the empty-full of Lygia Clark. In: The experimental exercise of freedom: Lygia Clark, Gego, Mathias Goeritz, Hélio Oiticica and Mira Schendel. CARVAJAL, Rina; RUIZ, Alma. (Org). Los Angeles: The Museum of Contemporary Art, 1999. [Moldase uma alma contemporânea: o vazio-pleno de Lygia Clark. Disponível em: http://www.pucsp.br/ nucleodesubjetividade/Textos/SUELY/Molda.pdf]

WHEELER, Dough; DACVIES, Hugh. Shining a light on light and space art. Disponível em: http:// articles.latimes.com/2011/sep/18/entertainment/la-ca-pst-hugh-davies-and-doug-wheeler-20110918. Acesso em: 20 dez. 2014.

WHITEHEAD, Alfred North. Process and Reality. New York: Free Press, 1978. 